\title{
Studi Oseanografi Guna Perencanaan Normalisasi Alur Pelayaran di Perairan Muara Sungai Kali Bodri, Kecamatan Patebon, Kabupaten Kendal
}

\author{
Dimas Nopriansyah ${ }^{1 *}$, Warsito Atmodjo ${ }^{1}$, Purwanto ${ }^{1}$, Denny \\ Nugroho Sugianto ${ }^{1}$ dan Aris Ismanto ${ }^{1}$ \\ Departemen Oseanografi, Fakultas Perikanan dan Ilmu Kelautan, Universitas Diponegoro, \\ J. Prof. Sudarto,SHTembalang Tlp. / Fax. (024)7474698 Semarang 50275 \\ *Email:nopriansyahdimas@gmail.com
}

\begin{abstract}
Abstrak
Muara Sungai Kali Bodri, Kecamatan Patebon, Kabupaten Kendal mengalami sedimentasi yang mengakibatkan pendangkalan alur pada mulut muara, sehingga mengganggu aktivitas pelayaran masyarakat nelayan setempat. Untuk normalisasi alur pelayaran muara Sungai Kali Bodri, dibutuhkan informasi terkait kondisi dan karakteristik oseanografi dan potensi pengendapan yang terjadi di muara sungai. Tujuan penelitian ini yaitu mengetahui kondisi oseanografi untuk perencanaan normalisasi kedalaman alur pelayaran di muara sungai dan perairan sekitar muara Sungai Kali Bodri, Kabupaten Kendal. Metode penelitian yang digunakan adalah metode pendekatan kuantitatif. Penelitian ini menggunakan pengukuran data gelombang lapangan yang diverifikasi dengan hasil peramalan gelombang angin untuk perhitungan gelombang pecah dan transport sedimen sepanjang pantai, pasang surut untuk acuan elevasi alur pelayaran, dimensi kapal untuk menetukan alur pelayaran, serta kedalaman perairan untuk mengetahui morfologi dan kemiringan pantai. Pengendapan akibat angkutan sedimen sepanjang pantai dengan kecepatan sebesar $0,901 \mathrm{~m} /$ det dan arah menuju ke arah barat mengikuti garis pantai. Nilai transpor sedimen sepanjang pantai yang terjadi pada mulut muara sungai adalah $1609,398 \mathrm{~m}^{3} /$ hari. Transpor sedimen sungai dihasilkan nilai sebesar $0,0246 \mathrm{~m}^{3} /$ hari hingga $0,0171 \mathrm{~m}^{3} /$ hari. Potensi pendangkalan alur yang terjadi di wilayah mulut muara sungai didominasi oleh gelombang laut. Perencanaan normalisasi alur pelayaran minimal, didapat lebar alur didapatkan 14,4 m untuk satu jalur dan 22,8 $\mathrm{m}$ untuk dua jalur dengan kedalaman alur sedalam 2,24 m, sehingga diperlukan pengerukan sebesar 1,62 $\mathrm{m}$ dari kondisi muara saat ini.
\end{abstract}

Kata kunci : Sedimentasi, Kali Bodri, Alur Pelayaran.

\begin{abstract}
Estuary of Kali Bodri River Patebon District, Kendal Regency experiencing sedimentation that results in the depth of estuary channel become superficial and make disruption of the local fisherman navigation activities. For normalization of Kali Bodri River channel, regarding information about the oceanographic conditions or characteristics and the potensial for sediment deposition that occurs at the river mouth and that become the purposes of this research. The method of this research used quantitative method. This research uses field wave data that is verified with wind wave forecasting for breaking wave and longshore sediment transport, tides for reference of navigation channel, ship dimensions for determine depth and width of navigation channel, and water morphology to determine morphology and beach slope. Sedimentation due to longshore sediment transport with velocity of 0,901 $\mathrm{m} / \mathrm{s}$ and the directions heading west follows the coastline. The value of longshore sediment transport that occurs at the mouth of estuary is $1609,398 \mathrm{~m}^{3} /$ day. The value of river sediment transport is 0,0246 $\mathrm{m}^{3} /$ day to $0,017 \mathrm{~m}^{3} /$ day. Sedimentation that occurs in the mouth of estuary is dominated by sea waves. Normalization planning for minimmum of navigation channel determined that the width of the channel is 14,4 $\mathrm{m}$ for one lane and 22,8 $\mathrm{m}$ for two lane with a depth is 2,24 $\mathrm{m}$, so with that conditions required dredging for 1,62 $\mathrm{m}$ from the current estuary conditions.
\end{abstract}

Keywords: Sedimentation, Kali Bodri, Navigation Channel 


\section{PENDAHULUAN}

Daerah aliran Sungai Kali Bodri merupakan daerah aliran sungai (DAS) yang paling besar dan dominan di wilayah pesisir Kabupaten Kendal. DAS Sungai Kali Bodri menghasilkan delta besar di Pantai Utara Pulau Jawa akibat laju sedimentasi yang tinggi yaitu sebesar $2,277-83,847 \mathrm{~kg} / \mathrm{m}^{2} / \mathrm{minggu}$ dan sangat dipengaruhi energi fluks gelombang yang sangat tinggi di wilayah tersebut, sehingga sedimen yang terbentuk di depan muara semakin besar (Sejati 1991 dalam Atmodjo 2010).

Muara sungai adalah bagian hilir dari sungai dan berhubungan dengan laut yang berfungsi sebagai pengeluaran debit sungai. Material sedimen yang melintas di depan muara akan terdorong oleh gelombang masuk ke muara dan kemudian diendapkan. Endapan yang sangat besar dapat menyebabkan tersumbatnya muara sungai dan dapat menyebabkan terjadinya banjir di daerah sebelah mulut muara. Pada musim penghujan air banjir dapat mengerosi endapan sedimen sedikit demi sedikit sehingga muara sungai dapat terbuka kembali. Selama proses penutupan dan pembukaan kembali yang terjadi, biasanya disertai dengan proses membeloknya mulut muara sungai dari bentuk sebelumnya. Hal tersebut pastinya mengakibatkan pendangkalan mulut muara yang menghambat alur pelayaran di sekitar muara Sungai Kali Bodri (Riandi et al., 2015).

Permasalahan tingginya tingkat sedimentasi dan pendangkalan yang signifikan di mulut muara juga terlihat jelas pada observasi lapangan, sehingga dapat mengganggu aktivitas nelayan sekitar Sungai Kali Bodri dan menjadi permasalahan utama dalam penelitian ini. Permasalahan tersebut harus dihadapi dengan langkah yang tepat, mengingat pentingnya pemanfaatan daerah tersebut untuk menunjang ekonomi penduduk yang mayoritas adalah sebagai nelayan. Sehubungan dengan kondisi tersebut sangat dibutuhkan langkah normalisasi muara untuk alur pelayaran, sehingga diperlukan informasi mengenai kondisi dan karakteristik oseanografi perairan muara Sungai Kali Bodri dan potensi pengendapan dari transpor sedimen sepanjang pantai yang terjadi akibat gelombang dan transpor sedimen daratan di perairan muara Sungai Kali Bodri.

Tujuan dari penelitian ini adalah untuk mengetahui kondisi oseanografi untuk perencanaan normalisasi kedalaman alur pelayaran di muara sungai dan perairan sekitar muara Sungai Kali Bodri, Kabupaten Kendal. Manfaat dari penelitian ini, diharapkan dapat memberikan informasi dan bahan pertimbangan kepada pihak terkait untuk tindak lanjut mengatasi permasalahan pengendapan muara yang terjadi di perairan muara Sungai Kali Bodri, Kecamatan Patebon, Kabupaten Kendal.

\section{MATERI DAN METODE}

Materi penelitian terdiri data primer dan data sekunder. Data primer yang digunakan adalah data gelombang yang menggunakan instrumen ADCP (Acoustic Doppler Current Profilier) selama tiga hari dilapangan, data morfologi dan kedalaman disekitar perairan pantai dan mulut muara Sungai Bodri menggunakan tongkat skala di titik yang direncanakan, data MPT di sekitar mulut muara sungai, serta data pasang surut selama tiga hari untuk validasi data pasang surut sekunder. Sedangkan data sekunder yang digunakan merupakan data pendukung yang berasal dari instansi terkait. Data sekunder yang digunakan adalah, Peta Rupa Bumi Indonesia wilayah Muara Sungai Bodri, Kendal dari BIG skala 1:25.000, Data pasang surut bulan Agustus 2019 yang diperoleh dari BIG stasiun Semarang, Data angin Wilayah Perairan Kendal selama sebelas tahun (2009-2019) yang berasal dari $E C M W F$, Data Batimetri sekunder wilayah perairan Muara Sungai Kali Bodri dari BATNAS, Data dimensi ukuran kapal nelayan yang berasal dari wawancara nelayan lokasi penelitian, Data debit aliran Sungai Kali Bodri dari Balai PSDA Sungai Kali Bodri

Dalam penelitian ini penulis menggunakan pendekatan kuantitatif. Menurut Creswell (2010) pendekatan kuantitatif adalah pengukuran data kuantitatif dan statistik objektif melalui perhitungan ilmiah berasal dari sampel orang-orang atau penduduk yang diminta menjawab atas sejumlah pertanyaan tentang survey untuk menentukan frekuensi dan prosentase tanggapan mereka. Dalam pendekatan kuantitatif ini penelitian akan bersifat pre-determinded, analisis data statistik serta interpretasi data statistik. Pendekatan yang akan dilakukan dalam penelitian ini adalah pendekatan analisis kuantitatif berdasarkan informasi statistika. 
Pendekatan penelitian yang dalam menjawab permasalahan penelitian memerlukan pengukuran yang cermat terhadap variable-variabel dari objek yang diteliti untuk menghasilkan kesimpulan yang dapat digeneralisasikan terlepas dari konteks waktu, tempat dan situasi.

Metode pengumpulan data, penentuan titik, dan analisis data menggunakan metode penelitian survei dan non survei. Metode survei dilakukan pengumpulan data/informasi yang berupa observasi, pengukuran dan pengambilan sampel secara langsung ke lapangan. Sedangkan metode non survei, dengan memperoleh data/informasi dari pihak lain, literatur, dan studi penelitian yang pernah dilakukan penelitian. Teknik pengambilan data dilakukan menggunakan alat dan instrumen penelitian serta wawancara untuk beberapa data, seperti dimensi kapal. Penentuan lokasi pengambilan data dilakukan dengan menggunakan metode purposive sampling. Metode purposive sampling adalah penentuan titik lokasi pengambilan data yang dapat mewakili kondisi daerah pengamatan secara keseluruhan (Aji et al., 2013). Titik pengambilan data dilakukan dengan menggunakan GPS. Titik pengambilan data yang dimaksud adalah titik pengambilan data pasang surut, gelombang dan kedalaman perairan. Lokasi titik pengambilan data lapangan tersaji pada Gambar 1.
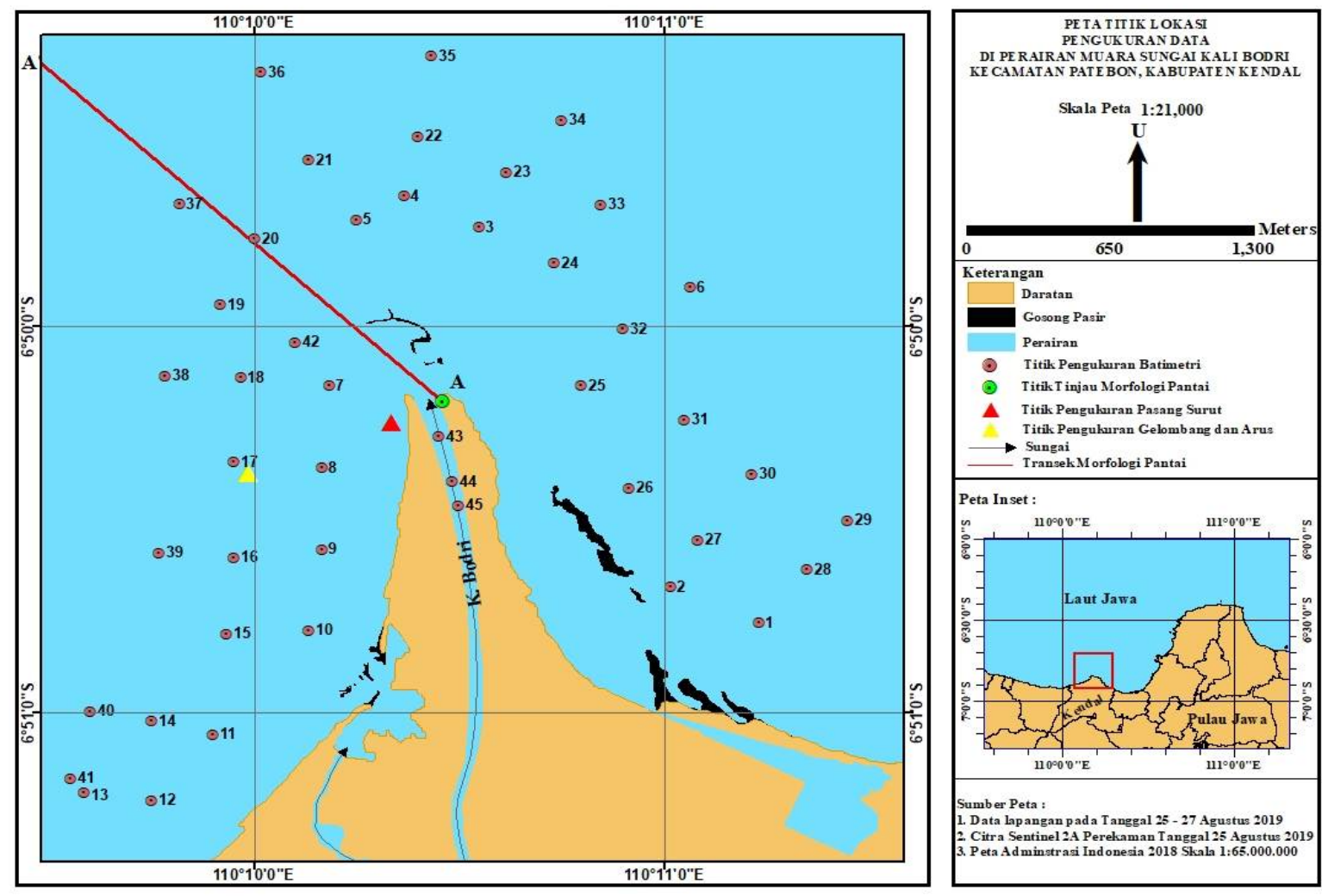

Gambar 1. Peta Lokasi Titik Pengambilan Data (Pengolahan Data, 2020).

\section{HASIL DAN PEMBAHASAN}

\section{Pasang Surut}

Pengukuran pasang surut di lokasi penelitian selama 3 hari dari tanggal 25 Agustus hingga 27 Agustus 2019 dengan interval 1 jam digunakan untuk verifikasi data pasang surut peramalan yang diperoleh dari BIG pada waktu yang sama saat waktu pengukuran di lapangan. Hasil pengukuran pasang surut lapangan diperoleh elevasi pasang surut tertinggi sebesar 1,1 $\mathrm{m}$ dan nilai terendah 0,44 $\mathrm{m}$. Data pasang surut sekunder BIG dalam waktu yang sama dengan pengukuran lapangan diperoleh nilai elevasi tertinggi sebesar $1,37 \mathrm{~m}$ dan nilai terendah $0,42 \mathrm{~m}$. Perbandingan kedua data antara data pasang surut lapangan dan pasang surut BIG pada Gambar 2 yang menunjukkan bentuk dan kesesuaian yang hampir mirip dari kedua data tetapi berbeda nilainya, yang artinya data tetap bersifat baik dan akurat. Setelah analisis verifikasi data keduanya, diperoleh nilai verifikasi RMSE sebesar 0,3419. 


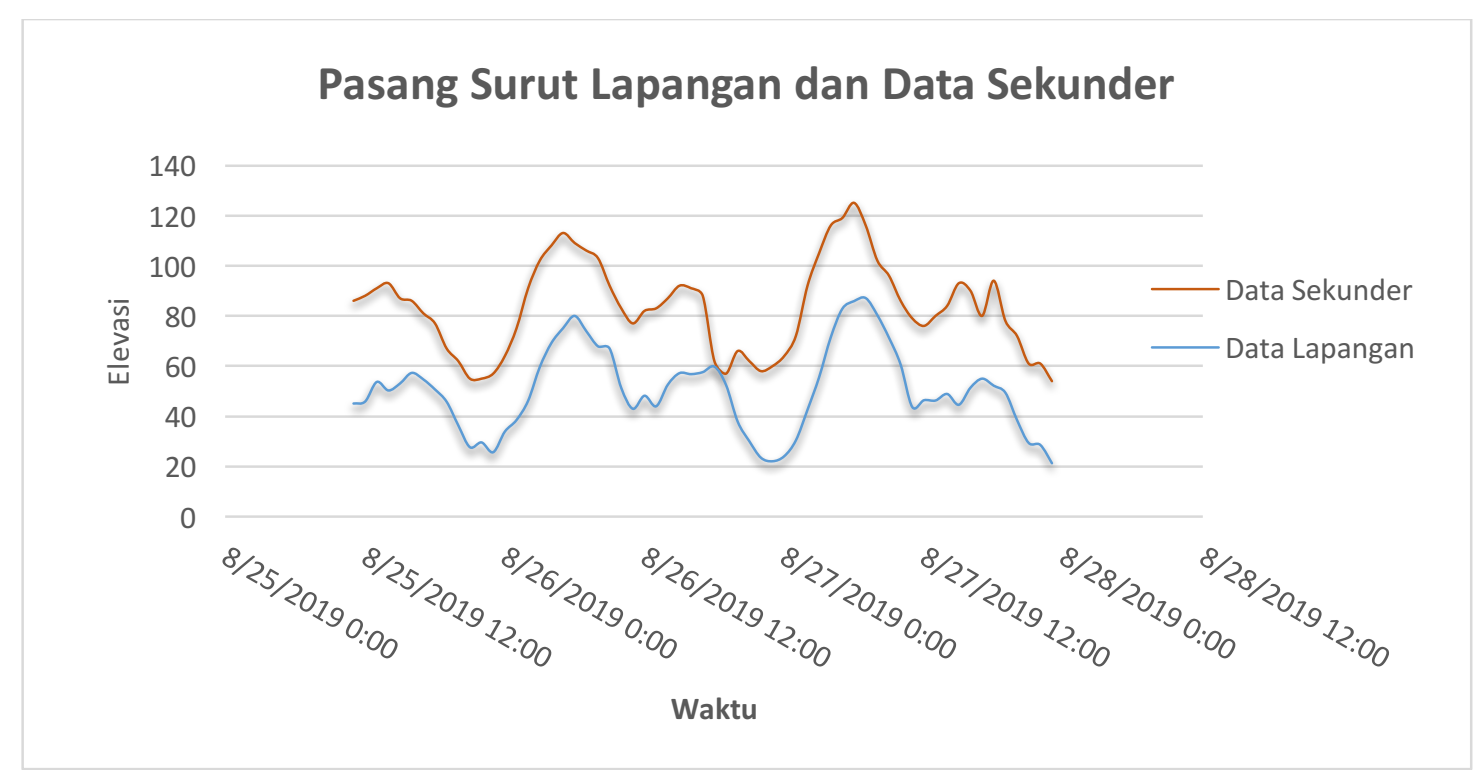

Gambar 2. Pasang Surut Lapangan dan Sekunder (Pengolahan Data, 2020).

Hasil perhitungan data pasang surut bulan Agustus 2019 menggunakan metode Admiralty 29 piantan menghasilkan nilai Formzhal 2,283. Berdasarkan klasifikasi pasang surut oleh Musrifin (2011) perairan dengan nilai Formzhal 2,283 termasuk dalam klasifikasi pasang surut campuran condong ke tunggal. Kedudukan muka air laut pasang surut diperoleh nilai elevasi pasang tinggi tertinggi (HHWL) sebesar 1,5 m, nilai elevasi surut rendah terendah (LLWL) sebesar 0,24 m akan menjadi acuan kedalaman alur pelayaran. Elevasi pasang surut lainnya yang diperoleh adalah nilai rata - rata muka air (MSL) sebesar $0,87 \mathrm{~m}$, nilai $\mathrm{Z}_{0}$ sebesar 0,63 , nilai ratarata muka air tertinggi (MHWL) sebesar 1,27 m dan rata - rata muka air terendah (MLWL) sebesar 0,46 $\mathrm{m}$. Grafik elevasi pasang surut Agustus 2019 dan kedudukan elevasinya disajikan dalam Gambar 3.

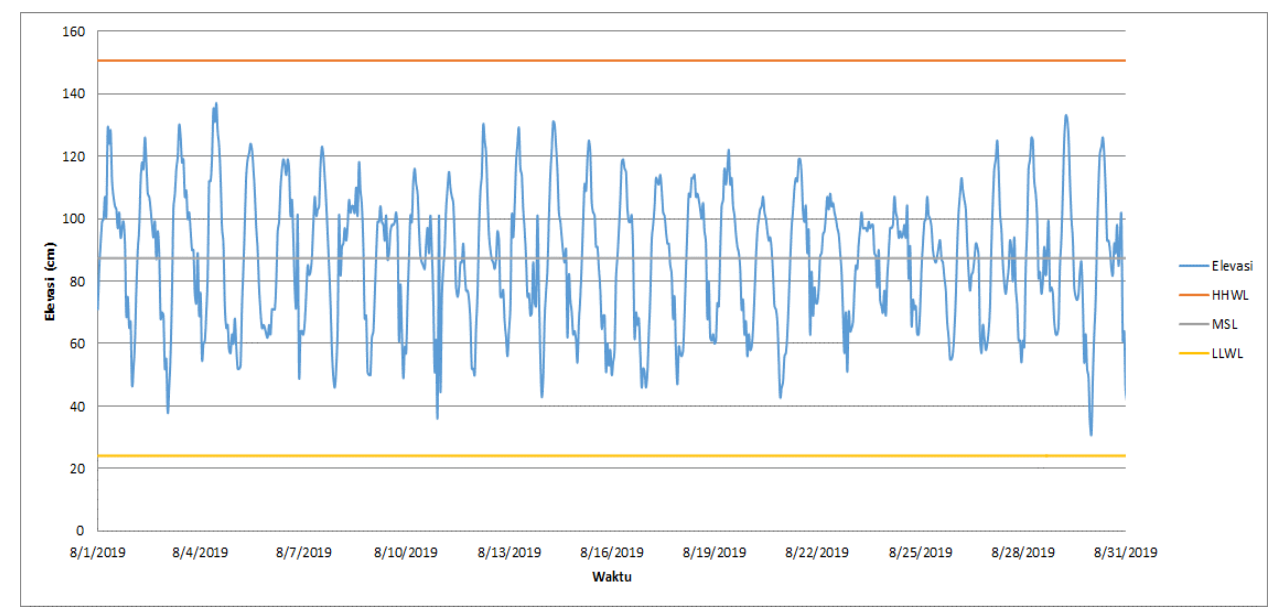

Gambar 3. Grafik Elevasi Pasang Surut Agustus 2019 (Pengolahan Data, 2020).

\section{Morfologi}

Hasil dari pengukuran kedalaman lapangan menghasilkan batimetri perairan dan memuat informasi morfologi perairan, kedalaman laut dan bentuk kontur dasar laut dari perairan Muara Sungai Kali Bodri Kendal. Pada kedalaman kurang dari $1 \mathrm{~m}$, terdapat gosong pasir di sekitar muara. Gosong pasir menyebabkan alur pelayaran terganggu akibat pendangkalan. Sebelah timur muara sungai juga terdapat gosong pasir yang berhadapan langsung dengan arah gelombang datang. Data pengukuran kedalaman diverifikasi dengan data kedalaman batimetri sekunder dari BATNAS menghasilkan RMSE sebesar 0,7114 yang artinya data lapangan baik untuk digunakan lebih lanjut. Analisa mengenai morfologi pada bagian mulut muara menuju laut dalam 
kearah barat laut, menghasilkan bentuk morfologi dasar perairan dengan nilai kelerengan pantai sebesar 0,0059 atau $0,59 \%$. Potongan morfologi perairan dengan kedudukan elevasi pasang surut digunakan untuk kepentingan peninjauan terhadap kelandaian pantai dari lokasi dan disajikan dalam Gambar 4.

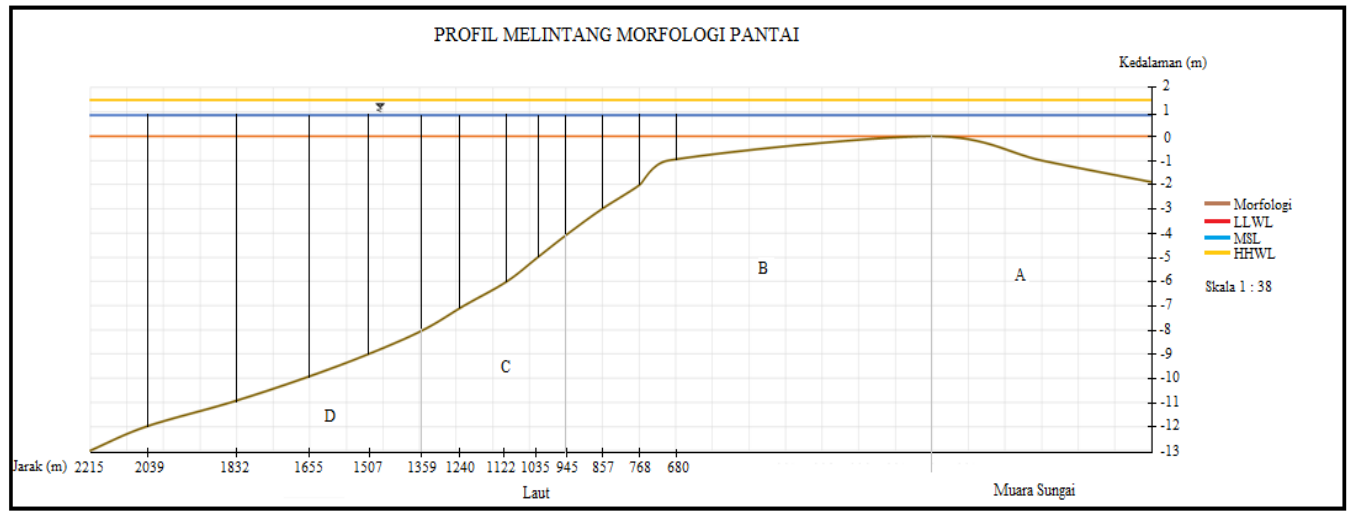

Gambar 4. Morfologi Perairan Dan Kedudukan Elevasi Pasang Surut (Pengolahan Data, 2020).

Peta batimetri pada Gambar 5 menunjukkan terdapat dua gosong pasir di mulut muara yang menandakan tingginya pengendapan yang terjadi di mulut muara akibat transport sedimen dari sepanjang garis pantai di wilayah muara sungai. Satu gosong pasir besar dan satu gosong pasir kecil. Pada saat pasang, gosong pasir kecil akan tertutup oleh air laut sedangkan gosong pasir besar masih ada sebagian kecil yang tidak tertutup air. Pada saat surut, daerah disekitar gosong pasir dan sekitar mulut muara akan sangat dangkal dengan kedalaman mencapai kurang dari 1 meter. Kedalaman muara sungai terukur pun berada pada rentang 1 hingga 2 meter yang kedalamannya sangat dangkal. Gosong pasir di depan mulut muara sungai ini memiliki bentuk yang cekung kearah sungai dan cembung kearah laut.
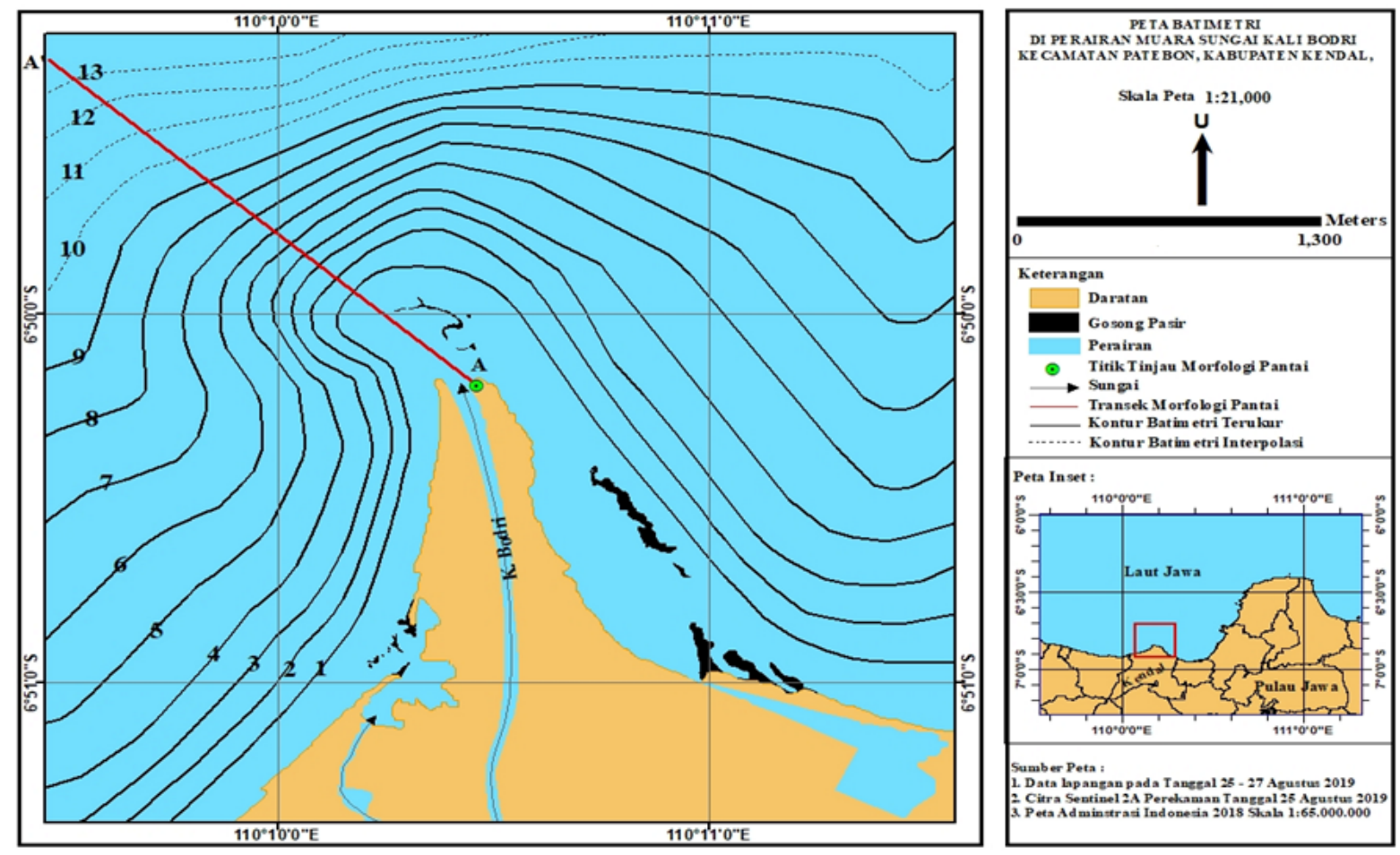

Gambar 5. Peta Batimetri (Pengolahan Data, 2020).

Gelombang 
Hasil analisis data angin diperoleh hasil arah angin selama 10 tahun yang tersaji dalam bentuk diagram mawar angin per musim. Pada musim barat menunjukkan bahwasannya arah angin dominan berasal dari Selatan menuju Utara atau $\mathrm{N} 187^{\circ}$ E musim peralihan 1 angin dominan berasal dari Timur Laut menuju Barat Daya atau $\mathrm{N} 17^{\circ} \mathrm{E}$, musim timur pada menunjukkan arah angin dominan berasal dari Timur Laut menuju Barat Daya atau $\mathrm{N} 35^{\circ} \mathrm{E}$, dan musim peralihan 2 menunjukkan arah angin dominan berasal dari Timur Laut menuju Barat Daya atau $\mathrm{N} 42^{\circ}$ E. Windrose musim timur disajikan dalam Gambar 6.

Hasil analisis data angin menunjukkan bahwa nilai tinggi dan periode gelombang peramalan semua musim yang memiliki nilai signifikan terbesar adalah karakteristik gelombang musim timur. Selain itu juga, karakteristik gelombang musim timur digunakan untuk verifikasi gelombang lapangan yang diambil pada musim timur. Hasil peramalan gelombang angin musim timur yaitu berupa tinggi gelombang signifikan (Hs) sebesar $0,732 \mathrm{~m}$, tinggi gelombang maksimum (H maks) sebesar $1,272 \mathrm{~m}$, tinggi gelombang rata-rata (H Rerata) sebesar $0,34 \mathrm{~m}$, dan tinggi gelombang minimum (H Min) sebesar $0,000025 \mathrm{~m}$. Hasil peramalan gelombang musim timur diperoleh data periode gelombang signifikan (Ts) sebesar 4,575 detik, periode gelombang maksimum (T maks) sebesar 6,069 detik, periode gelombang rata-rata (T Rerata) sebesar 2,752 detik, dan periode gelombang minimum (T Min) sebesar 0,043 detik.

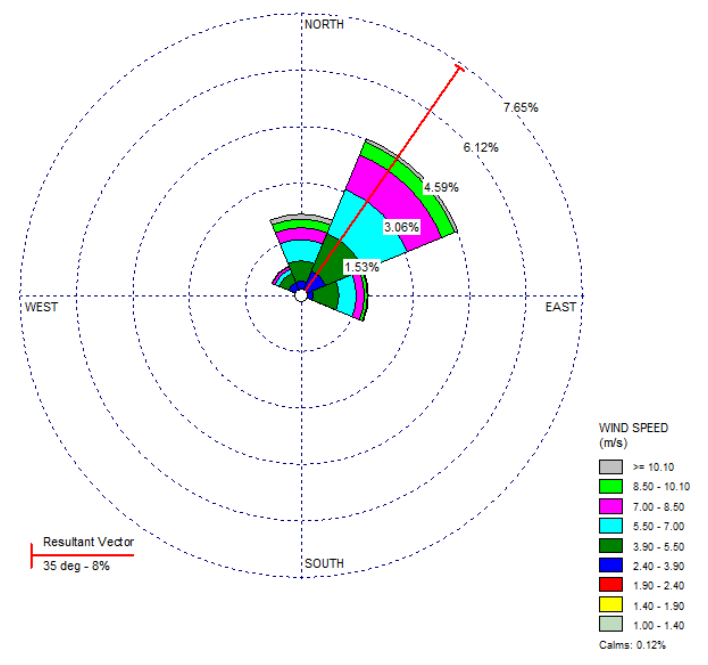

Gambar 6. Windrose Musim Timur Arah Utama Timur Laut (N 35 ${ }^{\circ}$ E) (Pengolahan Data, 2020).

Analisa gelombang lapangan diperoleh hasil tinggi gelombang signifikan (Hs) sebesar 0,123 $\mathrm{m}$, tinggi gelombang maksimum (Hmaks) sebesar $0,163 \mathrm{~m}$, tinggi gelombang rata-rata (H Rerata) sebesar 0,102 m, dan tinggi gelombang minimum (H Min) sebesar 0,006 m. Sama halnya dengan periode gelombang yang sudah di analisa akan memperoleh data periode gelombang signifikan (Ts) sebesar 4,66 detik, periode gelombang maksimum (Tmaks) sebesar 6,5 detik, periode gelombang rata-rata (T Rerata) sebesar 3,1 detik, dan periode gelombang minimum (T Min) sebesar 2,1 detik.

Hasil verifikasi gelombang menggunakan Root Mean Square Error (RMSE) dari tinggi dan periode hasil peramalan gelombang angin pada waktu yang bersamaan dengan hasil tinggi dan periode gelombang pengukuran lapangan, yaitu data musim timur yang menghasilkan verifikasi tinggi gelombang sebesar 0,273 dan verifikasi periode gelombang sebesar 1,138 pada Lampiran 15. Menurut Pradana (2016), hasil verifikasi dikatakan baik jika mendekati 0 , maka dari itu berdasarkan verifikasi gelombang, data baik untuk digunakan dalam perhitungan selanjutnya. Dengan demikian maka semua perhitungan dapat menggunakan data gelombang yang terukur.

Gelombang Pecah

Analisis gelombang pecah menggunakan data gelombang pada musim yang memiliki karakteristik gelombang terbesar. Menurut Triatmodjo (1999), acuan perhitungan dari gelombang yang digunakan adalah gelombang terbesar yang menjadi kemungkinan kondisi paling besar yang terjadi di wilayah tersebut. Dalam penelitian ini penggunakan gelombang dalam perhitungan adalah gelombang musim timur. Berdasarkan perhitungan gelombang angin pada musim timur, didapatkan nilai tinggi gelombang signifikan (Hs) sebesar 
0,732 $\mathrm{m}$ dan periode gelombang signifikan (Ts) sebesar 4,575 detik. Tinggi gelombang pecah $(\mathrm{Hb})$ sebesar $0,639 \mathrm{~m}$, kedalaman gelombang pecah $(\mathrm{db})$ sebesar $0,789 \mathrm{~m}$, panjang gelombang pecah $(\mathrm{Lb})$ sebesar 12,739 $\mathrm{m}$, cepat rambat gelombang pecah $(\mathrm{Cb})$ sebesar $2,783 \mathrm{~m} /$ det dan sudut arah datang gelombang pecah $(\alpha \mathrm{b})$ sebesar $19,73^{\circ}$. Arus sepanjang pantai dipengaruhi oleh arah datang gelombang dari laut dalam. Hasil analisa arus sepanjang pantai juga dapat melihat transport sedimen yang terjadi di sepanjang pantai wilayah muara sungai. Menurut CERC (1984), arus sepanjang pantai terjadi jika sudut gelombang pecah lebih dari $5^{0}$, dan analisis arah gelombang pecah menghasilkan nilai sebesar $19,73^{\circ}$, jadi di wilayah mulut muara sungai terjadi arus sepanjang pantai.

\section{Transpor Sedimen}

Daerah mulut muara Sungai Kali Bodri memiliki nilai arus sejajar pantai (V) sebesar 0,901 m/det diperoleh nilai transpor sedimen perhari (Qs) sebesar 1609,398 $\mathrm{m}^{3} /$ hari dan nilai transpor sedimen pertahun (Qs) sebesar 587471,4 $\mathrm{m}^{3} /$ tahun. Menurut Triatmodjo (1999), arah arus sejajar pantai akan dipengaruhi oleh arah gelombang datang. Dengan menggunakan sudut gelombang datang sebesar $60^{\circ}$ dan sudut gelombang pecah sebesar $19,73^{\circ}$, maka didapatkan hasil bahwa arah arus sejajar pantai berawal pada bagian timur muara sungai yang bergerak dari arah tenggara ke arah utara kemudian di daerah mulut muara sungai arahnya berbelok ke arah barat selanjutnya di barat muara sungai berbelok dari arah utara ke arah barat daya, yang arah datang gelombang berasal dari arah Timur Laut menuju ke garis pantai. Arah arus sejajar pantai disajikan dalam Gambar 7.
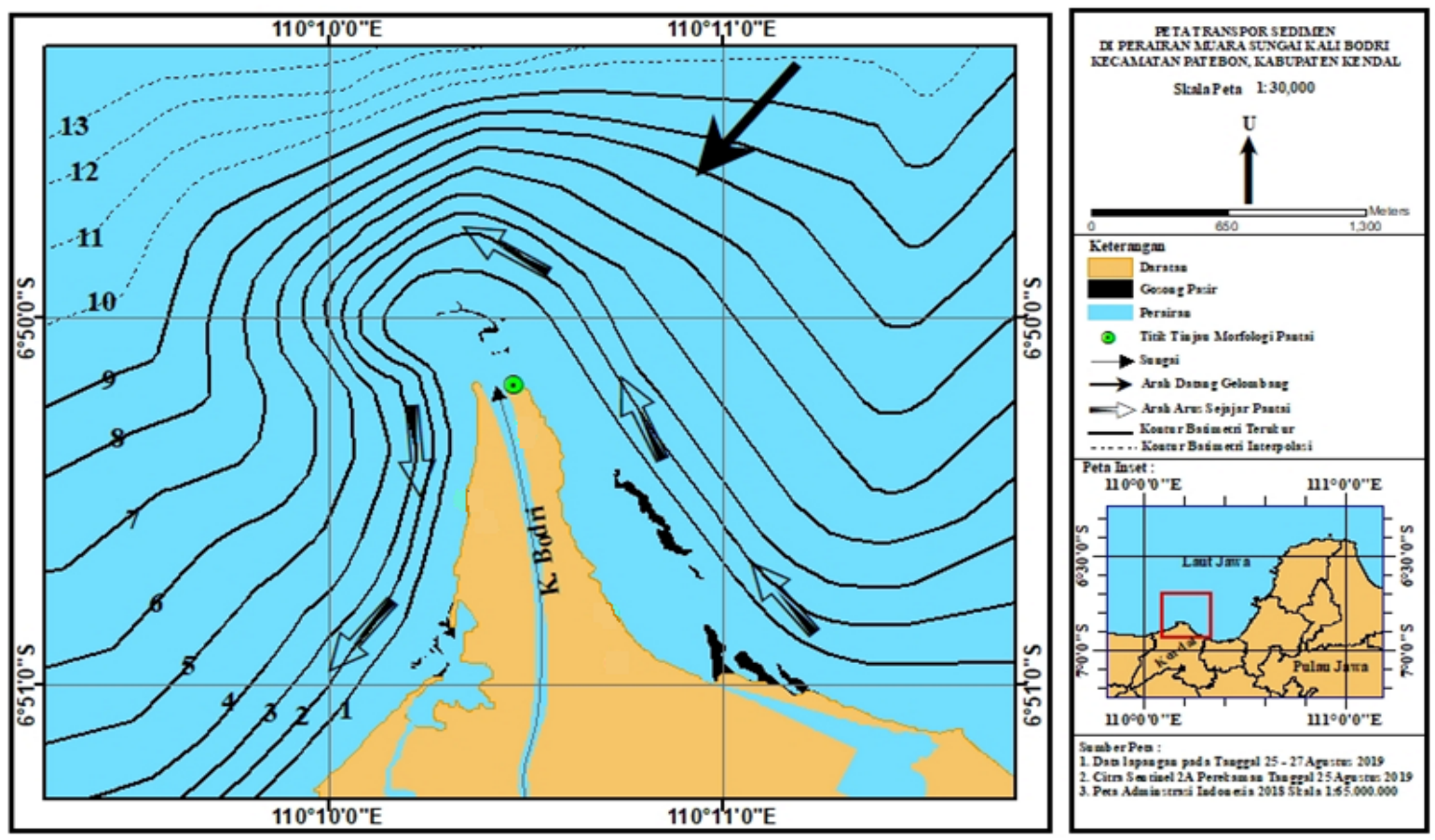

Gambar 7. Arah Datang Gelombang Dan Arus Sejajar Pantai (Pengolahan Data, 2020).

Analisis transport sedimen sungai menggunakan data konsentrasi material padatan tersuspensi (MPT) pada wilayah sekitar mulut muara Sungai Kali Bodri. Data MPT diperoleh dari tiga titik stasiun pengambilan sedimen tersuspensi yang beriringan dengan stasiun pengambilan kedalaman batimetri, yaitu stasiun 43,44 , dan 45. Transport sedimen sungai, dihasilkan pada stasiun 43 nilai transport sedimen sungai sebesar $0,0235 \mathrm{~m}^{3} /$ hari atau $8,577 \mathrm{~m}^{3} /$ tahun stasiun 44 transpor sedimen sungai sebesar $0,0246 \mathrm{~m}^{3} /$ hari atau $8,979 \mathrm{~m}^{3} /$ tahun dan stasiun 45 transpor sedimen sungai sebesar $0,0171 \mathrm{~m}^{3} /$ hari $6,2415 \mathrm{~m}^{3} /$ tahun.

Sedimen gosong pasir sejajar pantai menandakan bahwa sedimentasi yang terjadi di wilayah mulut muara sungai lebih dominan dipengaruhi oleh energi gelombang. Hal ini sesuai dengan pernyataan Davis (1968) dalam Atmodjo (2010), bahwasannya ciri muara yang didominasi oleh gelombang adalah adanya gosong pasir dengan morfologi pantani cembung ke arah laut. Berdasarkan pernyataan tersebut diketahui bahwa gosong pasir pada 
mulut muara sungai terbentuk akibat gelombang. Sedimen yang tidak terendapkan pada daerah timur muara sungai akan terbawa arus kearah Utara dan menuju daerah depan muara. Pada bagian depan muara sungai terjadi proses akresi akibat aliran sungai yang membawa sedimen dari daratan bertemu dengan gelombang datang yang membawa sedimen dari laut yang menyebabkan sedimen pasir berkumpul didepan muara sungai dan membentuk gosong pasir.

Mulut muara Sungai Kali Bodri menurut Arief et al. (2011), setiap tahun akan mengalami pembelokkan arah mulut muara. Hal ini juga terlihat di lapangan bahwasannya mulut muara condong ke arah barat daya dan tidak lurus terhadap alur aliran sungai yang menghadap utara. Pada muara sungai yang berbelok, dipengaruhi oleh angkutan sedimen sepanjang pantai yang arah datang gelombang berasal dari timur laut. Gelombang pecah yang membentuk sudut terhadap garis pantai menimbulkan limpasan energi yang dapat diuraikan menjadi komponen sepanjang pantai. Limpasan energi itulah yang menyebabkan arus sepanjang pantai dan transport sedimen sepanjang pantai. Transport sedimen tersebut akan menggerus pantai yang langsung berhadapan dengan arah gelombang datang, dan akan terangkut ke sepanjang pantai dan akan mengendap di sisi lain garis pantai. Proses ini akan terjadi terus menerus selama gelombang cukup besar sehingga mulut muara akan bergeser dan berbelok sesuai arah transport sedimen sepanjang pantai, dalam kasus muara Sungai Kali Bodri menuju arah barat dan akan menuju arah barat daya. Menurut Triatmodjo (1999), mulut muara sungai yang berpindah dan berbelok, menunjukkan bahwasannya muara didominasi oleh gelombang. Maka dari itu, hal ini juga menunjukkan bahwasannya muara Sungai Kali Bodri merupakan muara yang didominasi oleh gelombang laut.

\section{Alur Pelayaran}

Alur pelayaran yang sesuai dengan karakterisitik morfologi maupun hidro-oseanografi lokasi penelitian menggunakan acuan data ukuran kapal ikan terbesar, dengan panjang $7 \mathrm{~m}$, lebar kapal sebesar $3 \mathrm{~m}$, dan draft kapal sebesar 1,5 m yang melewati baik keluar maupun masuk mulut muara Sungai Kali Bodri Kendal. Alur pelayaran sendiri berorientasikan pada lebar alur serta kedalaman minimal yang sesuai untuk karakterisitk mulut muara. Analisis kedalaman alur pelayaran digunakan untuk mencari kedalaman aman minimal untuk dilewati kapal ukuran terbesar, dengan acuan dari kondisi surut terendah (LLWL) sebesar 0,24 $\mathrm{m}$ dan membandingkan dengan kondisi muka air rerata (MSL) sebesar $0,87 \mathrm{~m}$. Hasil perhitungan alur pelayaran yaitu kedalaman alur sebesar 2,24 $\mathrm{m}$ acuan LLWL dan 2,87 $\mathrm{m}$ acuan MSL serta lebar alur satu jalur sebesar 14,4 $\mathrm{m}$ pada Gambar 8 dan lebar alur dua jalur sebesar 22,8 m pada Gambar 9.

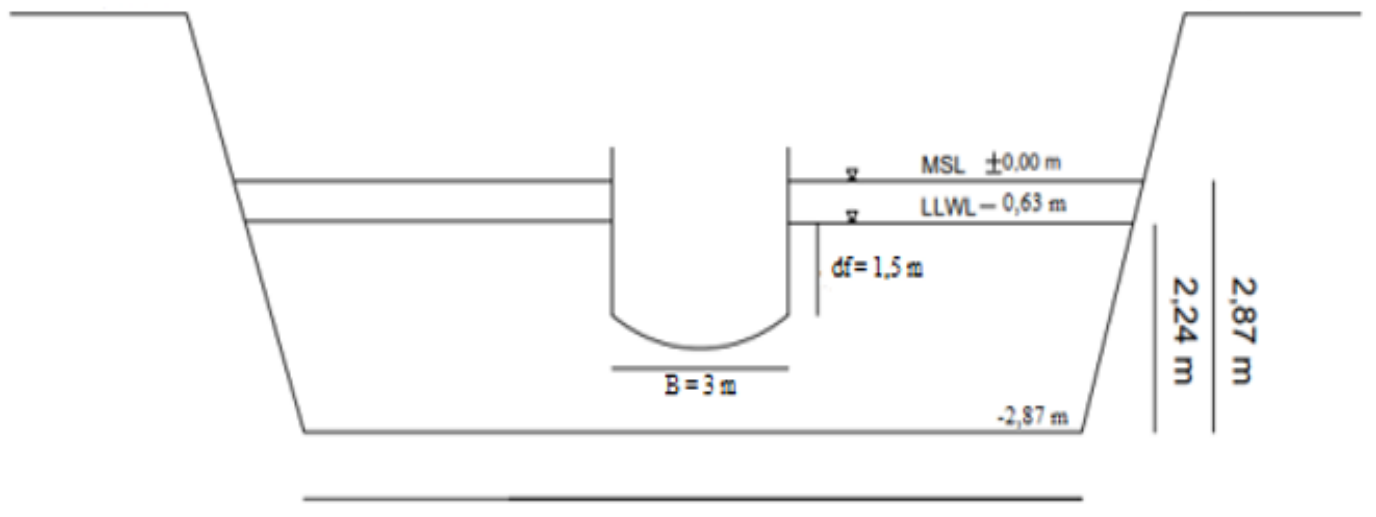

$14,4 \mathrm{~m}$

Gambar 8. Sketsa Alur Pelayaran Satu Jalur (Pengolahan Data, 2020). 


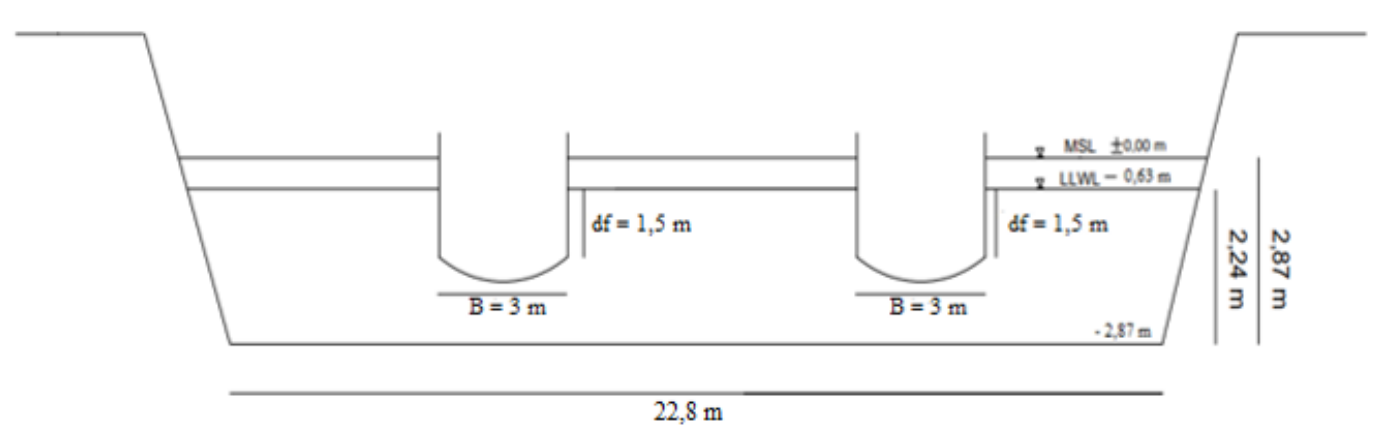

Gambar 9. Sketsa Alur Pelayaran Dua Jalur (Pengolahan Data, 2020).

Kondisi kedalaman muara digunakan untuk memperkirakan apakah kondisi kedalaman tersebut bisa digunakan atau tidak sebagai alur pelayaran yang aman. Kondisi kedalaman alur muara sungai terukur pada titik stasiun pengukuran kedalaman di muara, yaitu stasiun 43 , stasiun 44 dan stasiun 45 . Nilai kedalaman yang terukur di masing-masing stasiun adalah pada staisun 43 sebesar 1,29 m. stasiun 44 sebesar 1,25 m dan stasiun 45 sebesar 1,35 m. Hasil semua kedalaman muara dan kedalaman alur pelayaran menunjukkan bahwa perlunya melakukan tindakan pada alur agar dapat dilalui kapal nelayan dengan aman. Untuk mengatasi pendangkalan akibat sedimentasi ini, dapat dilakukan pengerukan secara berkala (maintainance dredging). Alur muara yang direncanakan lebih baik menghadap ke arah barat laut (N 300。 E). Hal ini tentunya berdasarkan arah datang gelombang yang berasal dari arah dominan timur laut dan menghindari secara langsung mulut muara berhadapan dengan gelombang datang serta menghindari langsung material yang dibawa gelombang laut menuju muara sungai dan terjadi pengendapan. Pengerukan yang diperlukan agar alur muara aman dilalui sesuai perencanaan kedalaman alur pelayaran adalah sebesar 1,53 m hingga 1,62 m pada masing-masing stasiun.

\section{KESIMPULAN}

Berdasarkan penelitian pada perairan muara Sungai Kali Bodri Kendal dapat disimpulkan arus sejajar pantai di mulut muara sungai memiliki kecepatan sebesar $0,901 \mathrm{~m} /$ det dan arah menuju ke arah barat mengikuti garis pantai dengan potensi pendangkalan alur yang terjadi di wilayah mulut muara sungai didominasi oleh gelombang laut. Nilai transpor sedimen yang terjadi pada mulut muara sungai adalah $1609,398 \mathrm{~m}^{3} /$ hari. Transport sedimen sungai dihasilkan nilai sebesar $0,0246 \mathrm{~m}^{3} /$ hari hingga $0,0171 \mathrm{~m}^{3} /$ hari. Alur pelayaran memiliki kedalaman alur 2,24 $\mathrm{m}$ dengan lebar alur pelayaran satu jalur sebesar 14,4 $\mathrm{m}$ dan lebar alur pelayaran dua jalur sebesar 22,8 m, sehingga diperlukan pengerukan sebesar 1,62 $\mathrm{m}$ di muara sungai.

\section{UCAPAN TERIMA KASIH}

Ucapan terima kasih saya sampaikan kepada Ir. Warsito Atmodjo, M.Si dan Ir. Purwanto, MT. yang telah mengarahkan dan membimbing selama berlangsungnya penelitianini.

\section{DAFTAR PUSTAKA}

Aji, I. N., Wibowo, B. A., \& Asriyanto, A. 2013. Analisis Faktor Produksi Hasil Tangkapan Alat Tangkap Cantrang Di Pangkalan Pendaratan Ikan Bulu Kabupaten Tuban. Journal of Fisheries Resources Utilization Management and Technology.

Arief, M. Winarso, G. \& Prayogo, T. 2011. Kajian Perubahan Garis Pantai Menggunakan Data Satelit Landsat Di Kec. Patebon, Kabupaten Kendal. Penginderaan Jauh.

Atmodjo, W. 2010. Sebaran Sedimen Di Perairan Delta Sungai Kali Bodri, Kendal, Jawa Tengah. Indonesian Journal of Marine Sciences, volume 15 (1): 53-58.

CERC. 1984. Shore Protection Manual Vol I. $4^{\text {th }}$ ed., U.S Army Coastal Enginerring Research Center, Washington D.C., 337p.

Creswell, J. W. 2010. Research design: pendekatan kualitatif, kuantitatif, dan mixed. Yogjakarta: PT Pustaka Pelajar.

Dauhan, S. Tawas, H. Tangkudung, T. Mamoto, J. 2013. Analisis Karakterisitk Gelombang Pecah Terhadap perubahan Garis Pantai Di Atep oki. Jurnal Sipil Statik, volume 1 (12) : 784-796.

George, M.S. L. Bertino, OM. Johannessen dan A. Samuelsen. 2010. Validation of a Hybrid Coordinate Ocean 
Model for The Indian Ocean. Journal of Operational Oceanography, volume 3 (2) :25-38.

Hadi, S dan Sugianto, D.N. 2012. Distribusi Kecepatan Angin Untuk Peramalan Gelombang Dengan Menggunakan Metode Derbyshire dan SMB di Perairan Semarang. Buletin Oseanografi Marina, volume 1: $25-32$.

Hendri, E. Ismanto, A. Saputro, S. 2016. Studi Pengaruh Gelombang Terhadap Transport Sedimen Di Perairan Timbulsloko Kabupaten Demak Jawa Tengah. Jurnal Oseanografi, volume 5 (1) : 77-85.

Kalay, D. Lopullisa, V. Noya, Y. 2018. Analisis Kemiringan Lereng Pantai Dan Distribusi Sedimen Pantai Perairan Negeri Waai Kecamatan Salahutu Provinsi Maluku. Jurnal Triton, 14 (1) : 10-18.

Liunsanda, M. Mamoto, J. Dundu, A. 2017. Perencanaan Bangunan Pengaman Pantai di Pantai Pal Kabupaten Minahasa Utara. Jurnal Sipil Statik, volume 5 (9):613-623.

Mawardi. 2016. Inovasi Mengatasi Pendangkalan Pada Pelabuhan Tapak Paderi Kota Bengkulu. Jurnal Inersia, volume 8 (1).

Mulerli, A. 2010. Dampak Angkutan Sedimen Terhadap Pembentukan Delta Di Muara Sungai Bone, Provinsi Gorontalo. Puslitbang Sumber Daya Air, Kementerian pekerjaan Umum.

Musrifin. 2011. Analsisi Pasang Surut Perairan Muara Sungai Mesjid Dumai. Jurnal Perikanan Kelautan, volume $16(1)$ : 48-55.

Paramitha, V.K., Yusuf dan Maslukah, L 2016. Sebaran Muatan Padatan Tersuspensi (MPT) di Perairan Karangsong, Kabupaten Indramayu. Jurnal Oseanografi., 5(2): 293 - 300.

Parauba, R. Jasin, M. Mamoto, J. 2016. Analisis Karateristik Gelombang Pecah Di Pantai Niampak Utara. Jurnal Sipil Statik, volume 4 (10): 595-603.

Pradana, R. A. 2016. Pemodelan Aliran Material Sedimen Akibat Arus Pasang Surut Untuk Pemeliharaan Kedalaman Perairan Pelabuhan (Studi Kasus: Pelabuhan Tanjung Perak-Teluk Lamong, Surabaya) (Doctoral dissertation, Institut Teknologi Sepuluh Nopember).

Pradipta, Y. Saputro, S. Satriadi, A. 2013. Laju Sedimentasi Di Muara Sungai Slamaran Pekalongan. Jurnal Oseanografi, 2(4) : 378-376.

Purba, N. P. 2014. Variabilitas Angin Ddn Gelombang Laut Sebagai Energi Terbarukan di Pantai Selatan Jawa Barat. Jurnal Akuaatika, volume 5(1):8-15.

Riandi, I. Ikhsan, M. Amir, A. 2015. Perencanaan Ulang Jetty Di Muara Batu Puti Meulaboh. Jurnal Teknik Sipil, volume 1 (1).

Riniatsih, I. 2015. Distribusi Muatan Padatan Tersuspensi (MPT) di Padang Lamun di Perairan Teluk Awur dan Pantai Prawean Jepara. Jurnal Kelautan Tropis., 18(3): 121 - 126.

Siswanto, A.D. 2007. Studi Aspek Geologi di Perairan Delta Bodri, Kabupaten Kendal. Embryo., 4(2): 114 123.

Strand, R.I., dan E.L. Pemberton. 1982. Reservoir Sedimentation Technical Guidelines for Bureau of Reclamation. U.S. Bureau of Reclamation, Denver, Colorado.

Triatmodjo,B. 1999. Teknik Pantai. Beta Offset, Yogyakarta.

Triatmodjo,B. 1996. Pelabuhan. Beta Offset, Yogyakarta.

Usman, K.O. 2014. Analisis Sedimentasi Pada Muara Sungai Komering Kota Palembang. Jurnal Teknik Sipil Universitas Sriwijaya, volume 2 (2). 